\title{
Characteristics of Nanophase WC and WC-3 wt\% (Ni, Co, and Fe) Alloys Using a Rapid Sintering Process for the Application of Friction Stir Processing Tools
}

\author{
Daeup Kim, ${ }^{1}$ Young Choi, ${ }^{1}$ Yongil Kim, ${ }^{2}$ and Seungboo Jung ${ }^{2}$ \\ ${ }^{1}$ Korea Institute of Industrial Technology (KITECH), 838-11 Palbok-dong 2-ga, Deokjin-gu, Jeonju, \\ Jeollabuk-do 531-202, Republic of Korea \\ ${ }^{2}$ SKKU Advanced Institute of Nanotechnology (SAINT), Sungkyunkwan University, 300 Cheoncheon-dong, Jangan-gu, \\ Suwon, Gyeonggi-do 440-746, Republic of Korea \\ Correspondence should be addressed to Daeup Kim; dukim@kitech.re.kr
}

Received 28 November 2014; Accepted 26 December 2014

Academic Editor: Kwangho Kim

Copyright (C) 2015 Daeup Kim et al. This is an open access article distributed under the Creative Commons Attribution License, which permits unrestricted use, distribution, and reproduction in any medium, provided the original work is properly cited.

\begin{abstract}
Microstructures and mechanical characteristics of tungsten carbide- (WC-) based alloys, that is, WC, WC-3 wt\% Ni, WC-3 wt\% Co, and WC-3 wt\% Fe, fabricated using a spark plasma sintering (SPS) method for the application of friction stir processing tools were evaluated. The sintered bodies with a diameter of $66 \mathrm{~mm}$ showed relative densities of up to $99 \%$ with an average particle size of $0.26 \sim 0.41 \mu \mathrm{m}$ under a pressure condition of $60 \mathrm{MPa}$ with an electric current for $35 \mathrm{~min}$ without noticeable grain growth during sintering. Even though no phase changes were observed after the ball milling process the phases of $\mathrm{W}_{2} \mathrm{C}$ and $\mathrm{WC}_{1-x}$ appeared in all sintered samples after sintering. The Vickers hardness and fracture toughness of the WC, WC-3 wt $\% \mathrm{Ni}$, WC-3 wt\% Co, and WC-3 wt $\%$ Fe samples ranged from $2,240 \mathrm{~kg} \mathrm{~mm}^{2}$ to $2,730 \mathrm{~kg} \mathrm{~mm}^{2}$ and from $6.3 \mathrm{MPa} \cdot \mathrm{m}^{1 / 2}$ to $9.1 \mathrm{MPa} \cdot \mathrm{m}^{1 / 2}$, respectively.
\end{abstract}

\section{Introduction}

The trend of energy savings and the enhanced environmental regulations have promoted the substitutional usage of lighter parts in industries recently. However, bonding two dissimilar materials has been a bottleneck to overcome in manufacturing process. Friction stir welding (FSW) that is well known for a joining process of dissimilar materials, especially aluminum-based alloys and other soft alloys, has been applied widely [1-5].

The FSW tool typically consists of a rotating round shoulder and a threaded cylindrical pin and heats up the workpiece mostly by mechanical friction and displaces the softened workpiece around it, eventually to form the bonding joint. Since FSW process does not involve the melting of bulk workpiece, the common problems of fusion welding such as the solidification and liquidation cracking, the porosity formation, and the loss of volatile alloying elements can be avoided. Compared to conventional other joining processes, FSW process sustains excellent mechanical properties of bonded joint and rarely deforms the workpiece after joining process, since process involves heating the workpiece minimally below the melting temperature and relatively localized joining area. However, the FSW tool itself can be subjected to severe stress and high temperatures, particularly for the cases of welding of hard alloys, such as steels and titanium alloys. Therefore, the commercial application of FSW to these alloys has been limited by the high cost and short life of FSW tools $[6,7]$. Although significant efforts $[8,9]$ have been made in order to develop cost-effective and reusable tools, most of the efforts have not been successful for the commercial applications and further work is needed for an improvement of tool to utilize the practice of FSW for joining of hard materials.

In general, WC has been widely used as processing tools because of an excellent mechanical strength with high melting point and wear resistance and therefore is considered to be a suitable candidate for a long life FSW tool with improved toughness by an addition of metal binders, such as cobalt and nickel. In order to make a WC tool, it is also 
critical to control the grain size because grain growth usually occurs during conventional sintering process of WC powder [10]. It was reported that an initial grain size increased more than five times during conventional sintering, hot pressing (HP), or hot isostatic pressing (HIP) processes [11]. Jeong et al. also reported that the particle size increased up to about $300 \mathrm{~nm}$ from $100 \mathrm{~nm}$ even with an addition of particle growth inhibitor [12].

Recently, the enhanced rapid sintering process called spark plasma sintering (SPS) has been developed for the dramatically reduced sintering time by employing highfrequency induction heating and pressure simultaneously, which reveals superior sintering properties $[13,14]$.

In the current study, the SPS process is employed to sinter WC powder with binders ( $\mathrm{Fe}, \mathrm{Ni}$, and $\mathrm{Co}$ ) for $35 \mathrm{~min}$ and the sintered bodies of a diameter of $66 \mathrm{~mm}$ were fabricated to form FSW tools. Effects of binder kind and composition on the microstructures and mechanical properties of sintered bodies were investigated and compared to the results of the previous research.

\section{Experimental Procedure}

In this study, $99.95 \%$ pure tungsten carbide $(0.5 \mu \mathrm{m}), 99.5 \%$ pure ferrum $(10 \mu \mathrm{m}), 99.5 \%$ pure nickel $(10 \mu \mathrm{m})$, and $99.5 \%$ pure cobalt $(10 \mu \mathrm{m})$ were used as powder materials. Horizontal ball milling was carried out at $250 \mathrm{rpm}$ for $48 \mathrm{~h}$ under the conditions that tungsten carbide and binders ( $\mathrm{Fe}, \mathrm{Ni}$, and $\mathrm{Co}$ ) were mixed with a weight ratio of $97: 3$ and the weight ratio of the powder to balls was $2: 1$. The particle sizes of initial powders and the ball milled powders were measured using a particle size analyzer.

After the mixed powders were placed in a graphite die (outside diameter, $140 \mathrm{~mm}$; inside diameter, $66 \mathrm{~mm}$; height, $160 \mathrm{~mm}$ ), it was sealed top and bottom by graphite punches. Then, it was placed into a system and spark plasma sintered as shown in Figure 1. A pressure of $60 \mathrm{MPa}$ was applied in vacuum and a 30,000 A current was imposed though punches during sintering process. Heating was carried out gradually as in Figure 2. When there is no more shrinkage displacement of the sintered body, the current was turned off and the sintered body was cooled in the chamber. The sintered bodies for FSW tool application were fabricated.

Apparent density was measured with the fabricated sintered bodies. Microstructure of the sintered bodies was observed after being etched using Murakami reagent (5 g $\mathrm{K}_{3} \mathrm{Fe}(\mathrm{CN})_{6}, 5 \mathrm{~g} \mathrm{NaOH}$, and $50 \mathrm{~mL}$ distilled water) for $4 \mathrm{~min}$ utes at room temperature. Qualitative and quantitative analysis were carried out for the phases through field-emission scanning electron microscopy (FE-SEM) and energy dispersive spectrometer (EDS). Also, phase analysis and grain size were measured using X-ray diffractometer. The mechanical properties of the sintered bodies were evaluated by hardness and fracture toughness. Hardness was taken using a Vickers hardness tester by performing indentation tests at a load of $30 \mathrm{kgf}$ and a dwell time of $15 \mathrm{~s}$. Fracture toughness was calculated with indentations produced via hardness measurement.

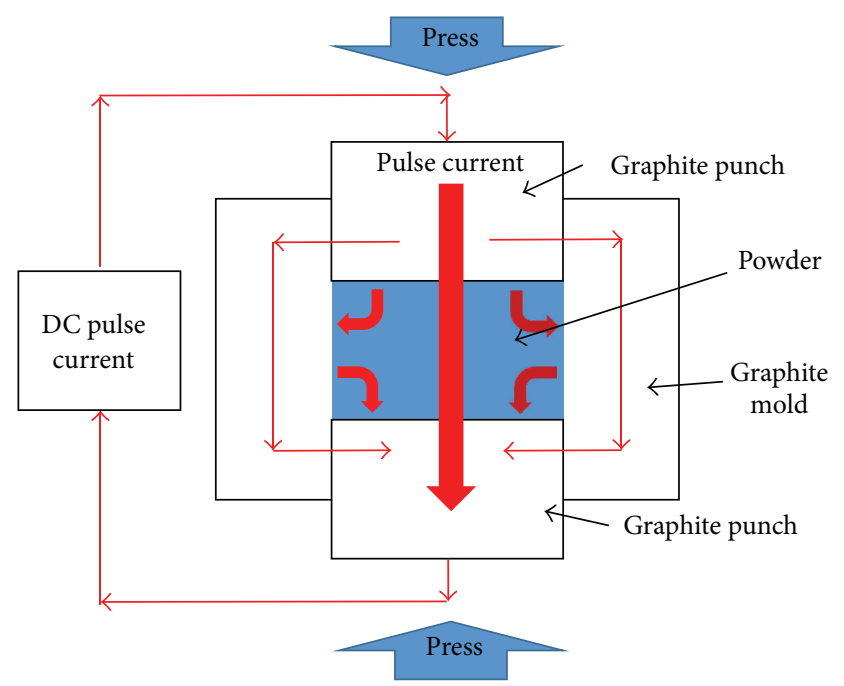

FIGURE 1: Schematic diagram of the apparatus for spark plasma sintering.

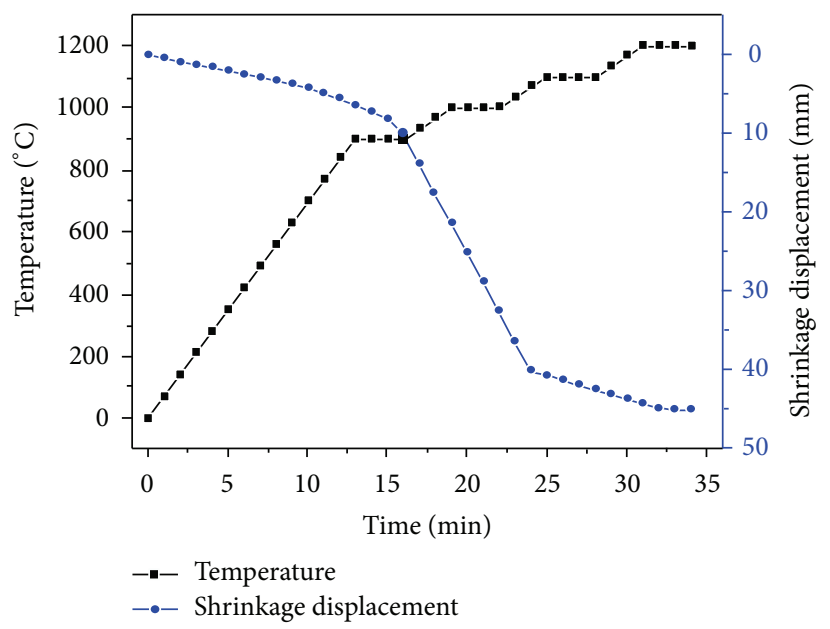

FIGURE 2: Variations of temperature and shrinkage as a function of heating time during spark plasma sintering of WC-3 wt $\%$ Co powder.

\section{Results and Discussion}

Figure 3 shows the FE-SEM images of WC and WC-3 wt $\% \mathrm{Ni}$, WC-3 wt $\%$ Co, and WC-3 wt $\%$ Fe powders after ball milling process. The initial powder size of $10 \mu \mathrm{m}$ was decreased in the size of $0.1 \sim 0.3 \mu \mathrm{m}$ in all powders after ball milling and also its values were similar to the result of particle size analyzer. All powders had sphere and polygonal shapes and were shown as the aggregation of the powder particles slightly. It seems that the initial powders with sphere and cylinder shapes were mixed enough during ball milling process because of pulverization between hard metal ball and the powder. The relative densities of $\mathrm{WC}, \mathrm{WC}-3 \mathrm{wt} \% \mathrm{Fe}, \mathrm{WC}-3 \mathrm{wt} \% \mathrm{Ni}$, and WC-3 wt $\%$ Co sintered bodies were measured after SPS process. They were shown to be $99.5 \%, 98.8 \%, 99.6 \%$, and $98.9 \%$, relatively. 


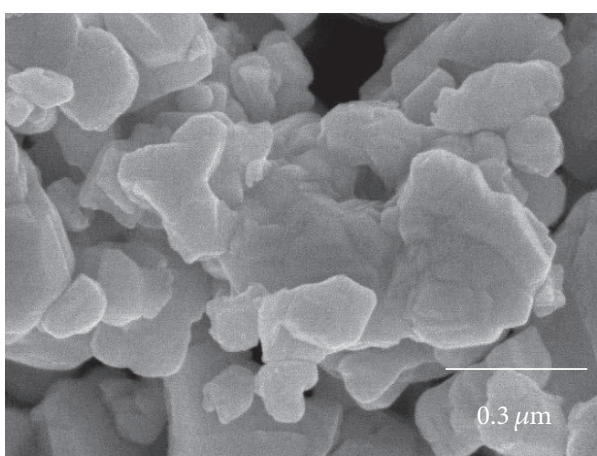

(a)

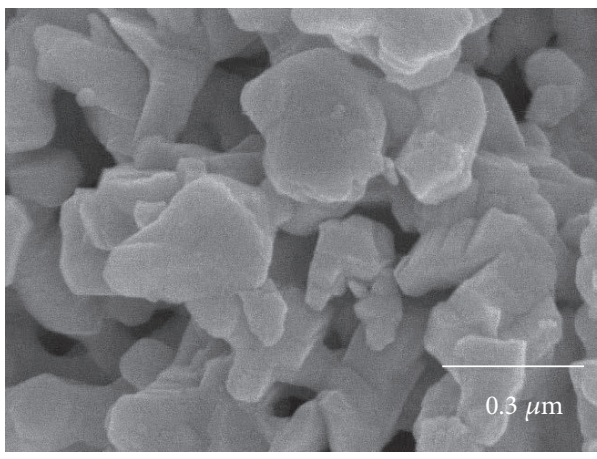

(c)

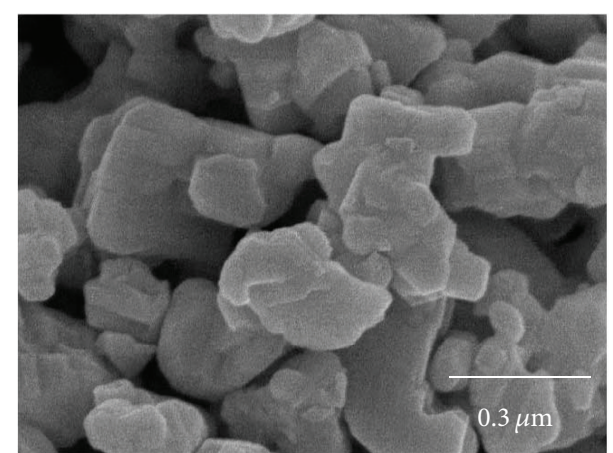

(b)

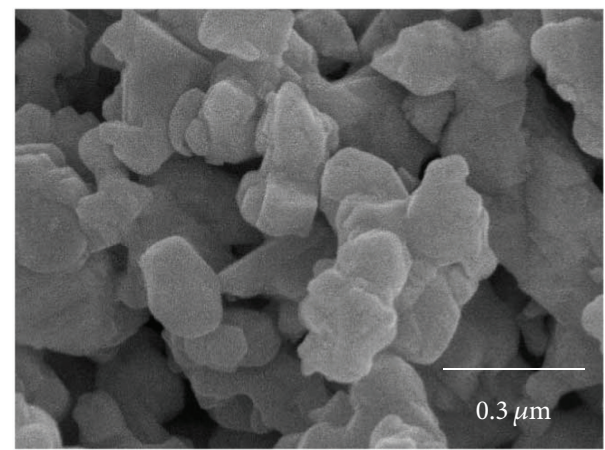

(d)

FIGURE 3: FE-SEM images of powders after ball milling: (a) WC, (b) WC-3 wt $\%$ Fe, (c) WC-3 wt\% Ni and (d) WC-3 wt\% Co.

Figure 4 shows the microstructure of each sintered body. Fine grains and dense structure were formed in the sintered bodies. Fine grains formed dense structure at all sintered bodies overall. The WC, WC-3 wt $\% \mathrm{Fe}$, and WC-3 wt $\% \mathrm{Ni}$ sintered bodies had polygonal grains structure and WC$3 \mathrm{wt} \%$ Co sintered body was observed to have the round shaped grains. In addition, WC was surrounded by $\mathrm{Fe}, \mathrm{Ni}$, and Co binders in the sintered bodies. Meanwhile, the grain size of each sintered body was measured by a linear analysis method. The average grain size of WC sintered body was about $0.45 \mu \mathrm{m}$ and it was slightly larger than that of WC$3 \mathrm{wt} \% X(X=\mathrm{Fe}, \mathrm{Ni}, \mathrm{Co})$ sintered bodies. In addition to the XRD analysis, the grain size was calculated using the Suryanarayana and Grant Norton's formula [15]:

$$
\operatorname{Br}\left(B_{\text {crystalline }}+B_{\text {strain }}\right) \cos \theta=\frac{k \lambda}{L}+\eta \sin \theta,
$$

where $\mathrm{Br}$ is the sum of $B_{\text {crystalline }}$ and $B_{\text {strain, }}$, meaning the increases in full width at half maximum (FWHM) by refinement and by strain, respectively. $k$ is the Boltzmann constant (with a value of 0.9 ), $\lambda$ is the wavelength of $\mathrm{X}$-ray radiation, $L$ is the grain size, $\eta$ is the strain, and $\theta$ is the Bragg angle. The average grain sizes of WC, WC- $3 \mathrm{wt} \% \mathrm{Fe}, \mathrm{WC}-3 \mathrm{wt} \% \mathrm{Ni}$, and WC-3 wt\% Co sintered bodies were shown to be $0.41 \mu \mathrm{m}$, $0.26 \mu \mathrm{m}, 0.30 \mu \mathrm{m}$, and $0.27 \mu \mathrm{m}$, respectively, and they were not significantly different in microstructure analysis. Grain growth did not occur in sintered bodies and also its size was almost the same as initial powder size; it seems that SPS process is processed with short time and single process. Kim et al. reported that the more the content of a binder increases, the more the sintering proceeds at low temperature. Thus, the grain size became smaller. As the content of a binder decreases, WC particles have chance to contact each other, which means easy particle growth. In this study, the grain size of WC sintered body was larger than the sintered bodies with binders due to the effect of added binders. Also, the grain size had no difference according to the composition of a binder and binder material does not have effect on the grain size.

On the basis of the microstructure observation as shown in Figure 4, mapping analysis was carried out by EDS to observe phases for each sintered body. Figure 5 shows the mapping result of WC-3 wt $\% \mathrm{Ni}$ sintered body. The $\mathrm{W}$ and $\mathrm{C}$ were distributed generally but $\mathrm{Ni}$ was distributed mainly around grain boundaries. Also, $\mathrm{Fe}$ and Co contents were distributed around the grain boundaries of WC in WC-3 wt $\%$ Fe and WC-3 wt\% Co sintered bodies. From these results, it was observed that $\mathrm{Fe}, \mathrm{Ni}$, and $\mathrm{Co}$ particles as binders smeared into gaps between WC particles during sintering and they surrounded the WC particles through liquid phase sintering. The result of qualitative and quantitative analysis in the midsection of WC-3 wt $\%$ Co sintered body is shown in Figure 6. There was no element except W, C, and Co in EDS analysis. The sintered body of the other compositions could obtain in the same result.

For each sintered body, XRD analysis was carried out to get detailed phase analysis before and after sintering. Figure 7 shows the analysis results after sintering, ball milling, and the initial powder of WC and WC-3 wt $\%$ Fe sintered body. The phase of WC and Fe existed in all initial powers and the ball milled powders. However the phases of $\mathrm{W}_{2} \mathrm{C}$ and $\mathrm{WC}_{1-x}$ in 


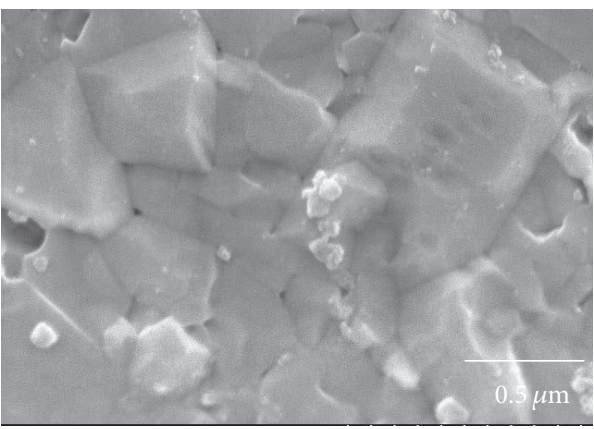

(a)

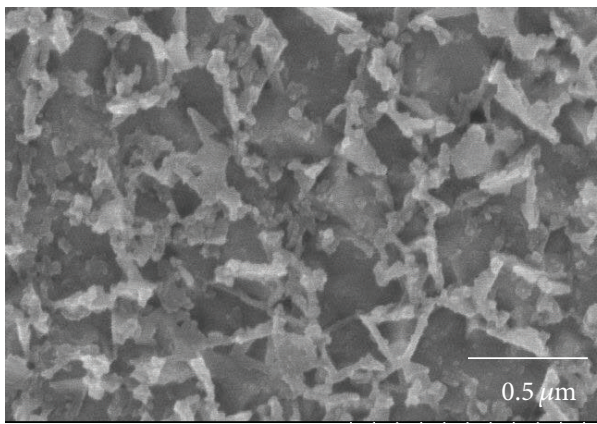

(c)

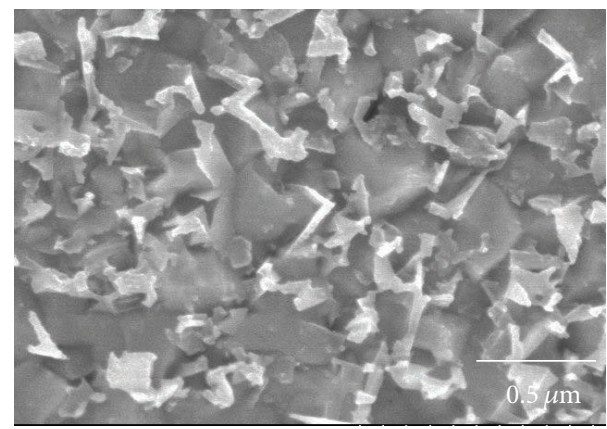

(b)

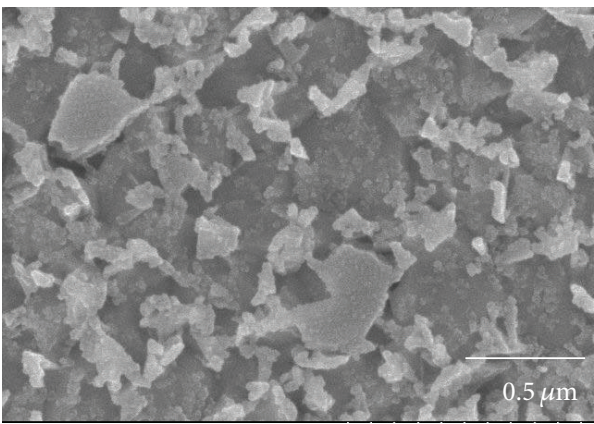

(d)

Figure 4: Microstructures of sintered hard materials: (a) WC, (b) WC-3 wt $\% \mathrm{Fe}$, (c) WC-3 wt $\% \mathrm{Ni}$, and (d) WC-3 wt $\%$ Co.
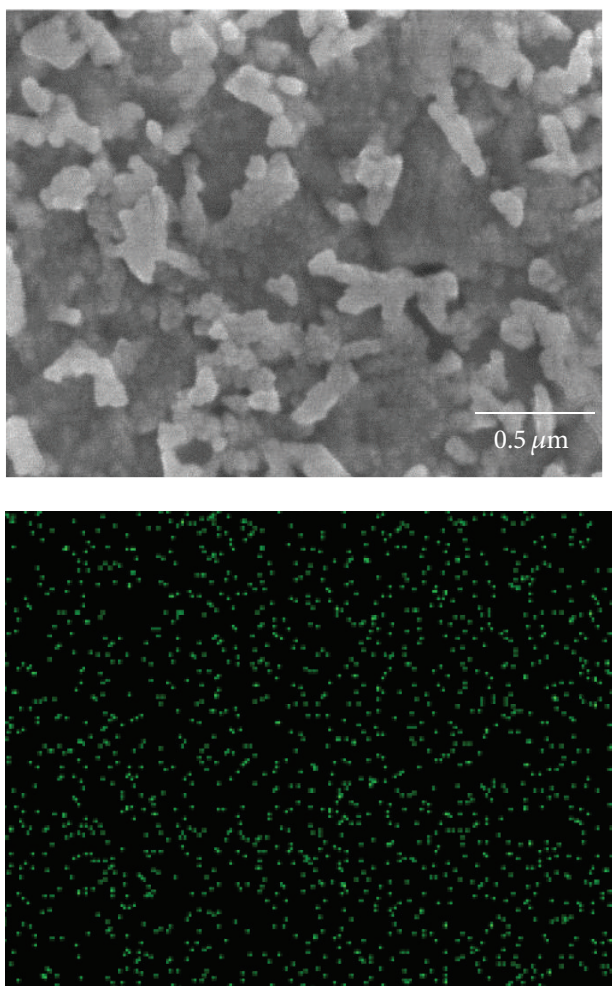

(b)

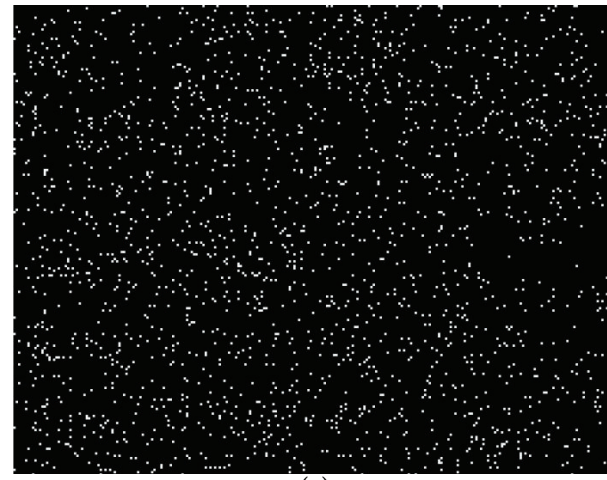

(a)

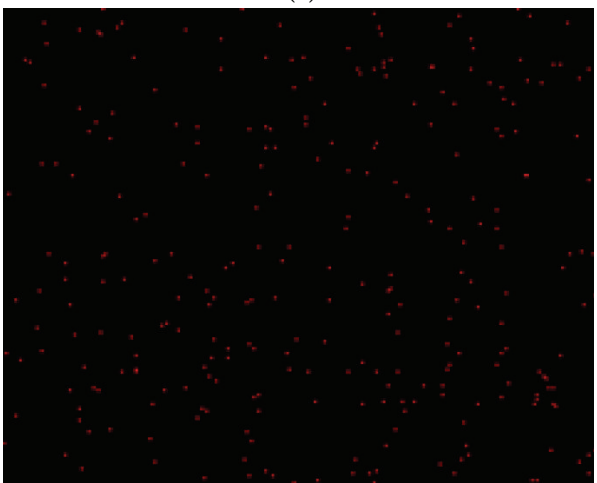

(c)

FIGURE 5: EDS mapping result of WC-3 wt $\% \mathrm{Ni}$ sintered body. 
TABLE 1: Mechanical properties of sintered hard materials.

\begin{tabular}{|c|c|c|c|c|c|}
\hline Sintered material (wt\%) & Relative density (\%) & Vickers hardness $(H v)$ & Fracture toughness $\left(\mathrm{MPa} \cdot \mathrm{m}^{1 / 2}\right)$ & Grain size $(\mu \mathrm{m})$ & Reference \\
\hline WC & 99.5 & 2,730 & 6.3 & 0.41 & \multirow{4}{*}{ This study } \\
\hline WC-3 Fe & 98.8 & 2,242 & 6.8 & 0.26 & \\
\hline WC-3 Ni & 99.6 & 2,240 & 9.1 & 0.30 & \\
\hline WC-3 Co & 98.9 & 2,269 & 7.4 & 0.27 & \\
\hline WC & 99 & 2,660 & 7.2 & 0.1 & [14] \\
\hline WC-2.9 Co & 98.3 & 2,014 & 6.5 & 0.94 & {$[19]$} \\
\hline WC-6 Co & 100 & 1,816 & 15.1 & 0.3 & {$[20]$} \\
\hline WC-10 Co & 98.9 & 1,333 & 13.5 & 1.9 & {$[21]$} \\
\hline WC-10 Co & 99.5 & 1,756 & 11.6 & 0.38 & {$[22]$} \\
\hline WC-10 Fe & 99.7 & 1,814 & 10.4 & 0.45 & {$[23]$} \\
\hline WC-9.6 Ni-0.4 Co & 99.5 & 1,180 & 12.5 & 1.8 & {$[24]$} \\
\hline
\end{tabular}

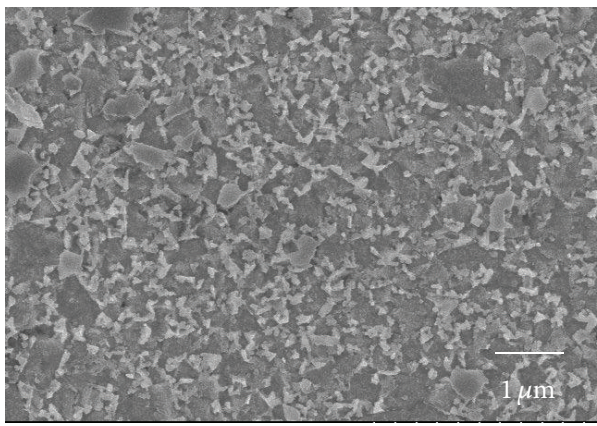

\begin{tabular}{ccc}
\hline Element & $(\mathrm{wt} \%)$ & (at\%) \\
\hline $\mathrm{W}$ & 84.09 & 28.32 \\
$\mathrm{C}$ & 13.40 & 69.05 \\
$\mathrm{Co}$ & 2.51 & 2.64
\end{tabular}

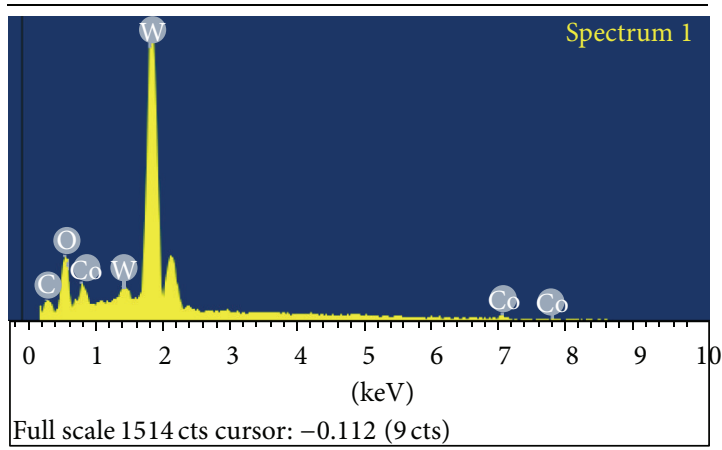

Figure 6: EDX analysis result of WC-3 wt\% Co sintered body.

all sintered bodies were observed after sintering. Kang et al. reported that only WC peaks were observed in WC sintered body after high-frequency induction heated sintering [14]. Also Youn et al. reported that phase change did not occur in $\mathrm{WC}-\mathrm{Mo}_{2} \mathrm{C}$-Co sintered body which is sintered by SPS process [16]. On the other hand, the $\mathrm{W}_{2} \mathrm{C}$ peaks were observed in the WC sintered body which is sintered by SPS at $1750^{\circ} \mathrm{C}$ [13]. When the liquid state of Co transformed the solid state during sintering in WC-10 wt\% Co using SPS process, Co with HCP crystalline structure transformed stabilized FCC structure after sintering [4]. In this study, the reason that $\mathrm{W}_{2} \mathrm{C}$ and $\mathrm{WC}_{1-x}$ phases appeared after sintering was that the oxide layer existed on surface of the initial powder reacted with carbon partially and then the content of carbon was decreased. To eliminate $\mathrm{W}_{2} \mathrm{C}$ phases, carbon of $0.5 \mathrm{wt} \%$ was added and the result showed no formation of the $\mathrm{W}_{2} \mathrm{C}$ phase [13].

In order to evaluate the mechanical properties of the sintered bodies, hardness and fracture toughness were evaluated using Vickers hardness tester. Table 1 shows the results of Vickers hardness measurement by performing indentation tests. Hardness of WC sintered body was about $2,730 \mathrm{~kg} \mathrm{~mm}^{2}$ and those of WC-3 wt $\%$ Fe, WC-3 wt $\% \mathrm{Ni}$, and WC-3 wt $\%$
Co sintered bodies were in the range from $2,240 \mathrm{~kg} \mathrm{~mm}^{2}$ to $2,269 \mathrm{~kg} \mathrm{~mm}^{2}$.

The cracks occurred from the indentation corner as shown in Figure 8. Fracture toughness was calculated by Niihara's formula with crack length:

$$
K_{\mathrm{IC}}=0.203\left(\frac{c}{a}\right)^{-3 / 2} \cdot H v \cdot a^{1 / 2}
$$

where $c$ is the trace length of the crack that was measured from the center of the indentation, $a$ is the half of diagonal length of indentation, and $H v$ is the Vickers hardness value. Table 1 shows the fracture toughness, the relative density, Vickers hardness value, and grain size from the sintered bodies synthetically and it was compared to other references. In this study, the fracture toughness value of $\mathrm{WC}-3 \mathrm{wt} \% \mathrm{Ni}$ sintered body was about $9.1 \mathrm{MPa} \cdot \mathrm{m}^{1 / 2}$, the highest among the four types. The fracture toughness of WC-3 wt $\%$ Fe and WC$3 \mathrm{wt} \% \mathrm{Co}$ was $6.8 \mathrm{MPa} \cdot \mathrm{m}^{1 / 2}$ and $7.4 \mathrm{MPa} \cdot \mathrm{m}^{1 / 2}$, respectively. Commonly, hardness and fracture toughness are significant factors to evaluate the mechanical properties in hard metals and they are affected by density, particle size, and content of a binder. The more the content of a binder increases, the more 


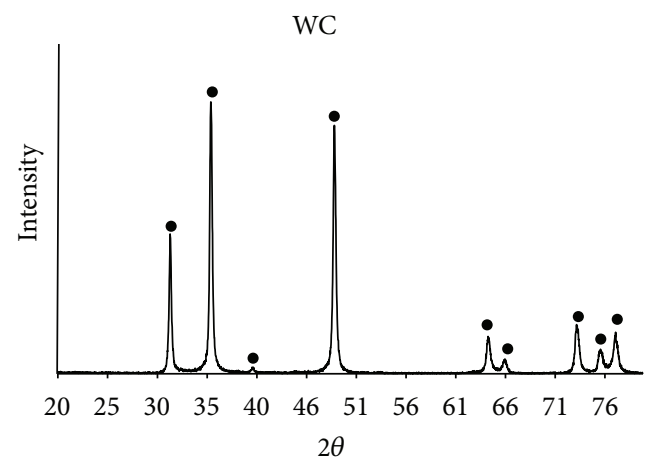

- WC

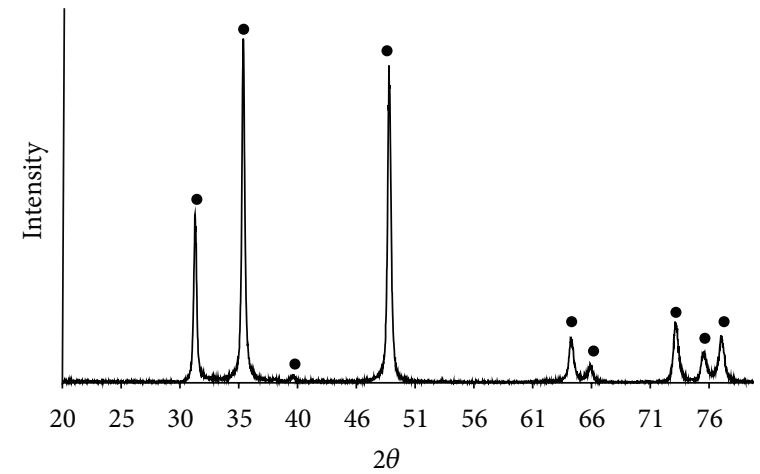

- WC

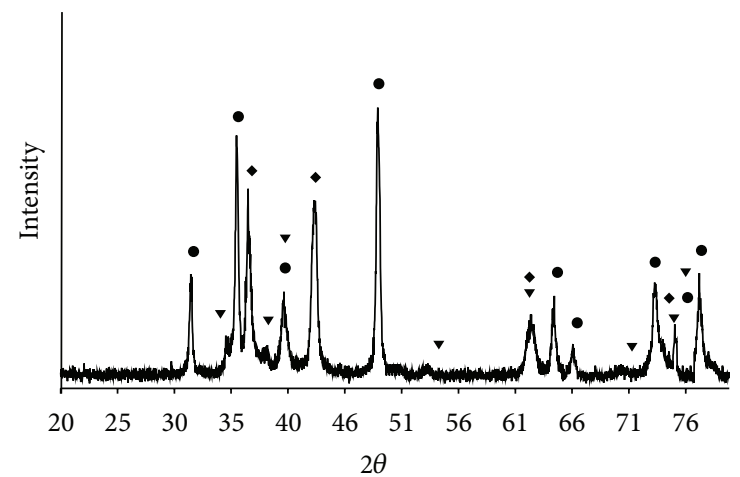

- WC

- $\mathrm{W}_{2} \mathrm{C}$

- $\mathrm{WC}_{1-x}$

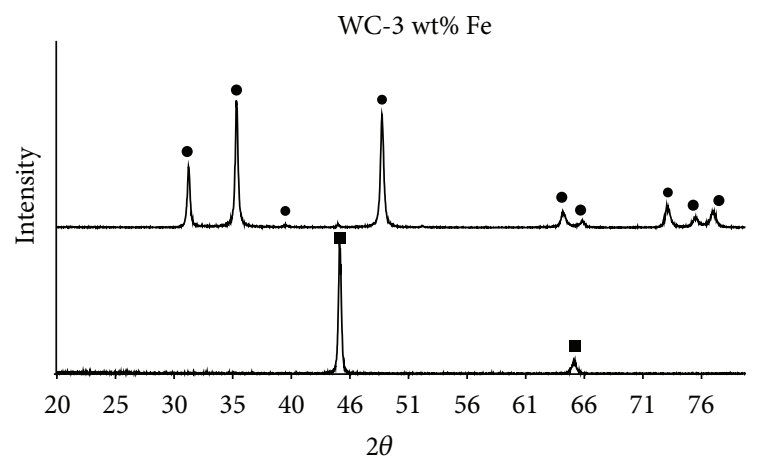

- WC

- $\mathrm{Fe}$

(a)

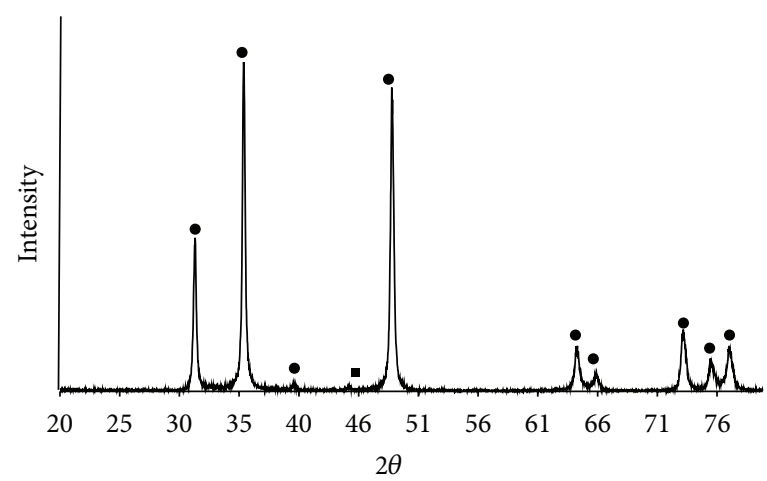

- WC

- $\mathrm{Fe}$

(b)

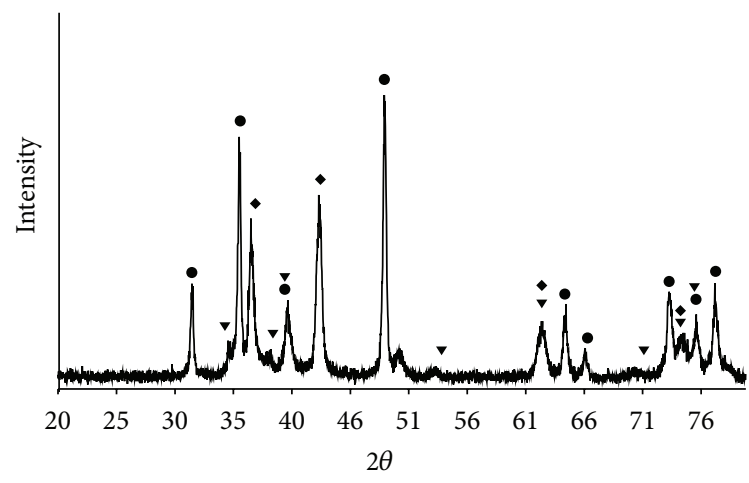

- WC

- $\mathrm{W}_{2} \mathrm{C}$

- $\mathrm{WC}_{1-x}$

(c) the thickness of a binder increases inside of particles; thus hardness increases and fracture toughness decreases [17]. According to the relation of Hall Petch, as the particle size of WC was smaller, hardness increases [18]. As mentioned above, the fracture toughness of sintered body added $\mathrm{Ni}$ as a binder indicates that it is higher than that of sintered body added Fe and Co. It is considered that the Fe and Co with
BCC crystalline structure have 4 slip systems while 12 slip systems of $\mathrm{Ni}$ with FCC crystalline structure contribute to improving of the fracture of sintered body. Compared to the result of the other research, hardness was little high but fracture toughness did not decrease in the same content of binders. In this study, $\mathrm{W}_{2} \mathrm{C}, \mathrm{WC}_{1-x}$ phases appeared after sintering but the grain growth did not occur because SPS 


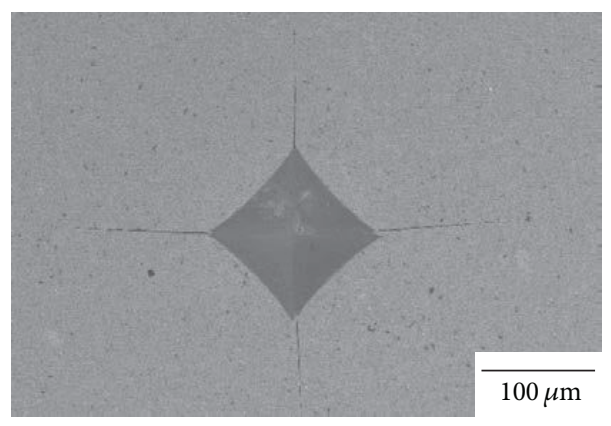

(a)

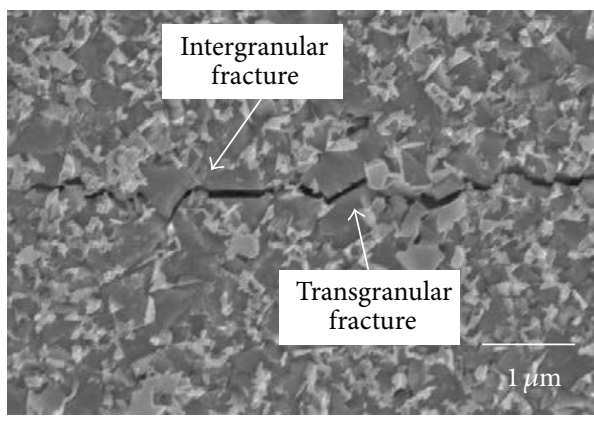

(c)

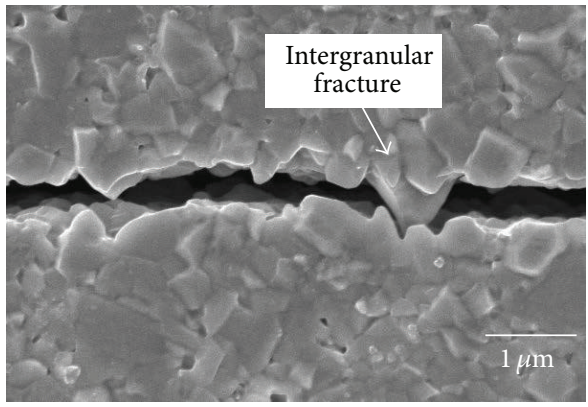

(b)

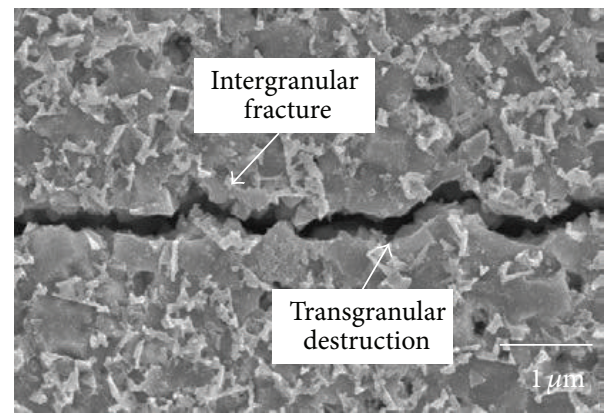

(d)

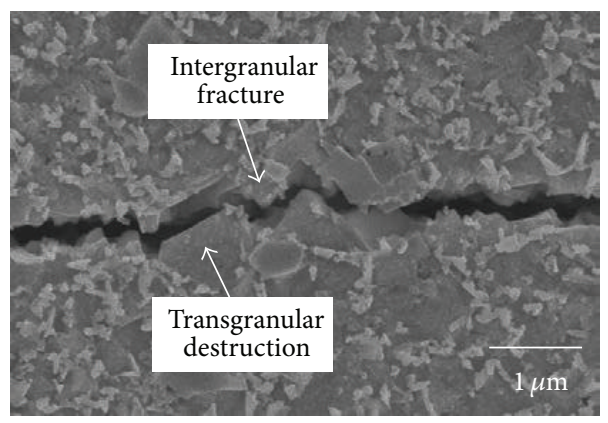

(e)

FIGURE 8: Vickers hardness indentation (a) and median crack propagation of sintered hard materials: (b) WC, (c) WC-3 wt\% Fe, (d) WC-3 wt\% $\mathrm{Ni}$, and (e) WC-3 wt\% Co.

process conducted in short amounts of time in comparison with HIP sintering. The relative densities of sintered bodies were about $99 \%$ and the dense sintered bodies without pores were made on surface and the center part. Considering the diameter of sintered body was about $66 \mathrm{~mm}$ which was bigger than other research results, sintered bodies in this study had excellent mechanical properties.

Figure 8 shows microstructures of propagated cracks from the indentation corner. Generally, most intergranular fractures are known to be caused by grain refinement and the hampered crack growth because cracks usually propagate along intergranular path rather than transgranular one; thus fracture toughness was increased [20]. Intergranular fracture was observed in the WC sintered body (b). Both transgranular and intergranular fractures were observed in the sintered bodies (c e) that $\mathrm{Fe}, \mathrm{Ni}$, and $\mathrm{Co}$ binders added. Also it was observed that fracture mode was shifted according to WC particles morphology. It was reported that the intergranular fracture occurred and fracture toughness was improved in nanosized metals [4]. In this study, most intergranular fractures and minor transgranular fractures were observed and high hardness was obtained and fall of toughness was not observed. The following is the reason of obtaining high strength sintered bodies. Localized high temperature heating and rapid atomic diffusion occurred by a direct current in relatively low sintering temperature within a short time. The superior sintered bodies is characterized by the applied pressure of sintering which serves as a driving force and thereby increases sintering density. Also, Fe, Ni, and $\mathrm{Co}$ binders made the stable sintered bodies that liquid phase changed into solid phase on the interface of WC particle. The FSW tool requiring high hardness was considered to have suitable characterization.

\section{Conclusion}

Tungsten carbide- (WC-) based alloys, that is, WC, WC$3 \mathrm{wt} \% \mathrm{Ni}$, WC-3 wt $\% \mathrm{Co}$, and WC-3 wt $\%$ Fe powders, were 
mixed by ball milling and fabricated using a spark plasma sintering method. The microstructures and mechanical characteristics were evaluated. The following is the conclusion.

(1) The density of the sintered bodies was about $99 \%$ and the average grain size was in the range from 0.26 to $0.41 \mu \mathrm{m}$. The sintered bodies were obtained without almost grain growth during sintering.

(2) WC, WC-3 wt\% Fe, and WC-3 wt \% Ni sintered bodies had polygonal grains and WC-3 wt $\%$ Co had slightly round shape grains. Fine and dense microstructure was observed.

(3) By EDS analysis, the contents of $\mathrm{W}$ and $\mathrm{C}$ were distributed generally while $\mathrm{Fe}, \mathrm{Ni}$, and Co content as a binder mainly surrounded the grain boundary of WC.

(4) Only initial phase existed in initial powers and the ball milled powders but the phases of $\mathrm{W}_{2} \mathrm{C}$ and $\mathrm{WC}_{1-x}$ in all sintered bodies were observed after sintering.

(5) Hardness and fracture toughness of sintered WC were $2,730 \mathrm{~kg} \mathrm{~mm}{ }^{2}, 6.3 \mathrm{MPa} \cdot \mathrm{m}^{1 / 2}$, and those of WC$3 \mathrm{wt} \% \mathrm{Fe}, \mathrm{WC}-3 \mathrm{wt} \% \mathrm{Ni}$, and $\mathrm{WC}-3 \mathrm{wt} \%$ Co sintered body were $2,240 \mathrm{~kg} \mathrm{~mm}^{2} \sim 2,269 \mathrm{~kg} \mathrm{~mm}^{2}$ and $6.8 \sim$ $9.1 \mathrm{MPa} \cdot \mathrm{m}^{1 / 2}$, relatively. The fracture toughness of WC-3 wt\% Ni showed the highest value among four types.

(6) WC-3 wt $\%(X=\mathrm{Fe}, \mathrm{Ni}, \mathrm{Co})$ sintered bodies showed good mechanical property for FSW tool due to its high density and small grain size.

\section{Conflict of Interests}

The authors declare that there is no conflict of interests regarding the publication of this paper.

\section{References}

[1] P. B. Srinivasan, W. Dietzel, R. Zettler, J. F. dos Santos, and V. Sivan, "Stress corrosion cracking susceptibility of friction stir welded AA7075-AA6056 dissimilar joint," Materials Science and Engineering A, vol. 392, no. 1-2, pp. 292-300, 2005.

[2] K.-S. Bang, K.-J. Lee, and H.-S. Bang, "Interfacial microstructure and mechanical properties of dissimilar friction stir welds between 6061-T6 aluminum and Ti-6\%Al-4\% V alloys," Materials Transactions, vol. 52, no. 5, pp. 974-978, 2011.

[3] Y. S. Sato, Y. Kurihara, S. H. C. Park, H. Kokawa, and N. Tsuji, "Friction stir welding of ultrafine grained $\mathrm{Al}$ alloy 1100 produced by accumulative roll-bonding," Scripta Materialia, vol. 50, no. 1, pp. 57-60, 2004.

[4] H.-K. Park, H.-J. Youn, J.-H. Ryu et al., "Fabrication and mechanical properties of WC-10 wt.\% Co hard materials for a friction stir welding tool application by a spark plasma sintering process," Journal of Ceramic Processing Research, vol. 13, no. 6, pp. 705-712, 2012.

[5] K. Nakata, Y. G. Kim, H. Fujii, T. Tsumura, and T. Komazaki, "Improvement of mechanical properties of aluminum die casting alloy by multi-pass friction stir processing," Materials Science and Engineering A, vol. 437, no. 2, pp. 274-280, 2006.
[6] Y. S. Sato, H. Yamanoi, H. Kokawa, and T. Furuhara, "Microstructural evolution of ultrahigh carbon steel during friction stir welding," Scripta Materialia, vol. 57, no. 6, pp. 557560, 2007.

[7] K. Lee and K. Bang, "Interfacial microstructure of dissimillar friction stir welds between $\mathrm{Al}$ and Ti alloy sheet," Journal of Korean Welding and Joining Society, vol. 28, pp. 5-19, 2010 (Korean).

[8] K. Lee, S. Kim, H. Park, and I. Oh, "Development of the tool for friction stir welding of high temperature materials," Journal of Korean Welding and Joining Society, vol. 29, no. 5, pp. 54-57, 2011 (Korean).

[9] T. Miyazawa, Y. Iwamoto, T. Maruki, and H. Fujii, "Development of Ir based tool for friction stir welding of high temperature materials," Proceedings of the Japan Welding Society, vol. 86, article 43, 2010 (Japanese).

[10] A. Couret, G. Molénat, J. Galy, and M. Thomas, "Microstructures and mechanical properties of TiAl alloys consolidated by spark plasma sintering," Intermetallics, vol. 16, no. 9, pp. 11341141, 2008.

[11] K. Jia, T. E. Fischer, and B. Gallois, "Microstructure, hardness and toughness of nanostructured and conventional WC-Co composites," Nanostructured Materials, vol. 10, no. 5, pp. 875891, 1998.

[12] I. K. Jeong, J. H. Park, J. M. Doh et al., "Mechanical properties and consolidation of ultra-fine WC-10Co and Wc-10Fe hard materials by rapid sintering process," Journal of the Korean Institute of Metals and Materials, vol. 46, no. 4, pp. 223-226, 2008.

[13] J. Zhao, T. Holland, C. Unuvar, and Z. A. Munir, "Sparking plasma sintering of nanometric tungsten carbide," International Journal of Refractory Metals and Hard Materials, vol. 27, no. 1, pp. 130-139, 2009.

[14] H.-S. Kang, J.-M. Doh, K.-T. Hong, I.-Y. Ko, and I.-J. Shon, "Rapid sintering of nanostuctured tungsten carbide by highfrequency induction heating and its mechanical properties," Journal of Korean Institute of Metals and Materials, vol. 48, no. 11, pp. 1009-1013, 2010.

[15] C. Suryanarayana and M. G. Norton, X-Ray Diffraction: A Practical Approach, Plenum Press, New York, NY, USA, 1998.

[16] H. Youn, H. Bang, I. Oh, and H. Park, "Fabrication and mechanical properties of $\mathrm{WC}-\mathrm{Mo}_{2} \mathrm{C}$-Co hard materials by the pulsed current activated sintering method," Journal of Korean Institute of Metals and Materials, vol. 50, no. 12, pp. 921-929, 2012.

[17] K. Niihara, R. Morena, and D. P. H. Hasselman, "Evaluation of $\mathrm{K}_{I c}$ of brittle solids by the indentation method with low crackto-indent ratios," Journal of Materials Science Letters, vol. 1, no. 1, pp. 13-16, 1982.

[18] Y. V. Milman, S. Chugunova, V. Goncharuck, S. Luyckx, and I. T. Northrop, "Low and high temperature hardness of WC-6 wt\%Co alloys," International Journal of Refractory Metals and Hard Materials, vol. 15, no. 1-3, pp. 97-101, 1997.

[19] C.-D. Park, H.-C. Kim, I.-J. Shon, and Z. A. Munir, "Onestep synthesis of dense tungsten carbide-cobalt hard materials," Journal of the American Ceramic Society, vol. 85, no. 11, pp. 26702677, 2002.

[20] H.-K. Park, S.-M. Lee, H.-J. Youn, K.-S. Bang, and I.-H. Oh, "Fabrication and mechanical properties of ultra fine WC6 wt.\%co by spark plasma sintering process," Journal of Korean Institute of Metals and Materials, vol. 49, no. 1, pp. 40-45, 2011. 
[21] G. R. Anstis, P. Chantikul, B. R. Lawn, and D. B. Marshall, "A critical evaluation of indentation techniques for measuring fracture toughness: I, direct crack measurements," Journal of the American Ceramic Society, vol. 64, no. 9, pp. 533-538, 1981.

[22] L. S. Sigl and H. F. Fischmeister, "On the fracture toughness of cemented carbides," Acta Metallurgica, vol. 36, no. 4, pp. 887$897,1988$.

[23] J.-H. Han and D.-Y. Kim, "Determination of three-dimensional grain size distribution by linear intercept measurement," Acta Materialia, vol. 46, no. 6, pp. 2021-2028, 1998.

[24] H.-C. Kim, H.-K. Park, I.-K. Jeong, I.-Y. Ko, and I.-J. Shon, "Sintering of binderless WC- $\mathrm{Mo}_{2} \mathrm{C}$ hard materials by rapid sintering process," Ceramics International, vol. 34, no. 6, pp. 1419-1423, 2008. 

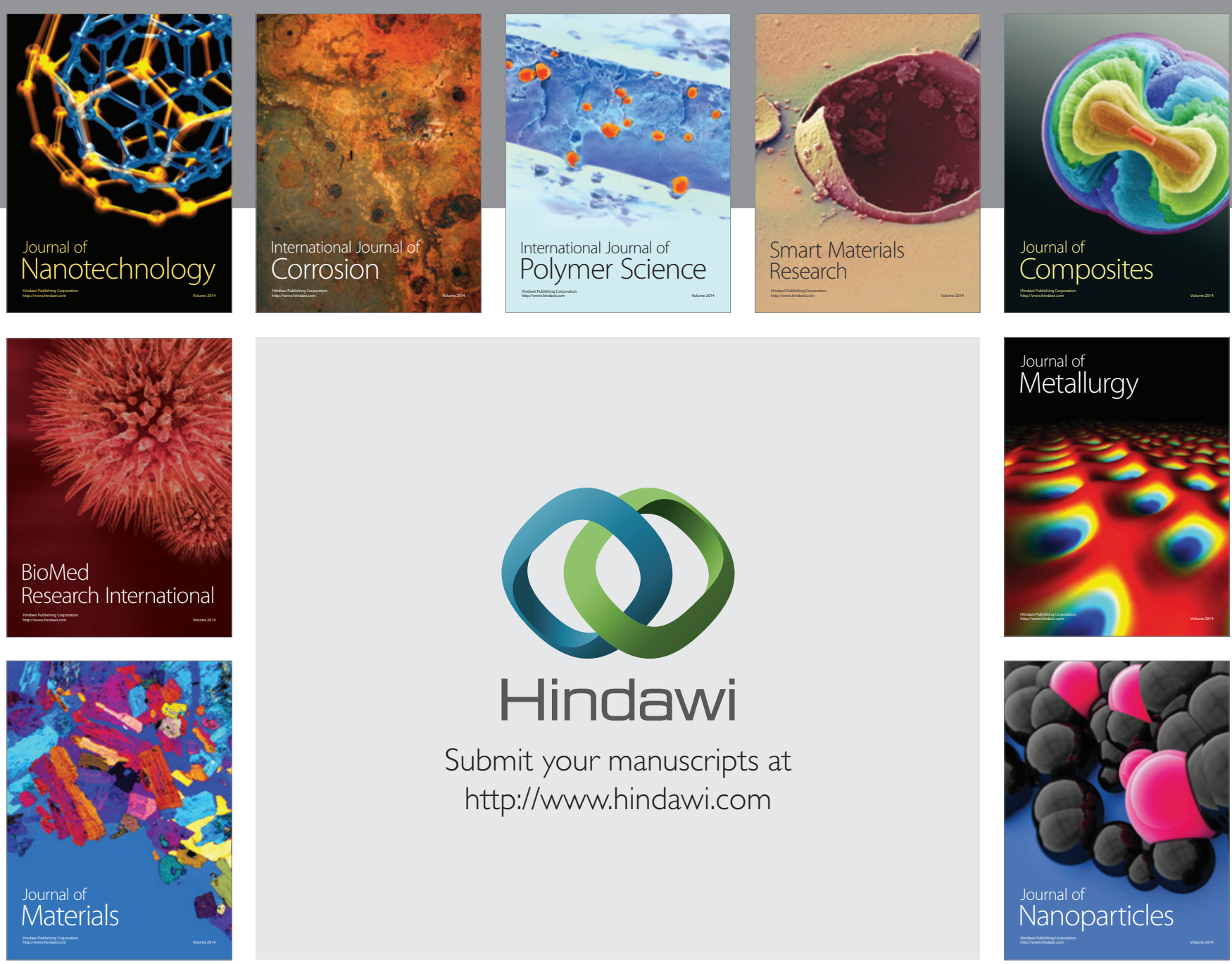

Submit your manuscripts at http://www.hindawi.com
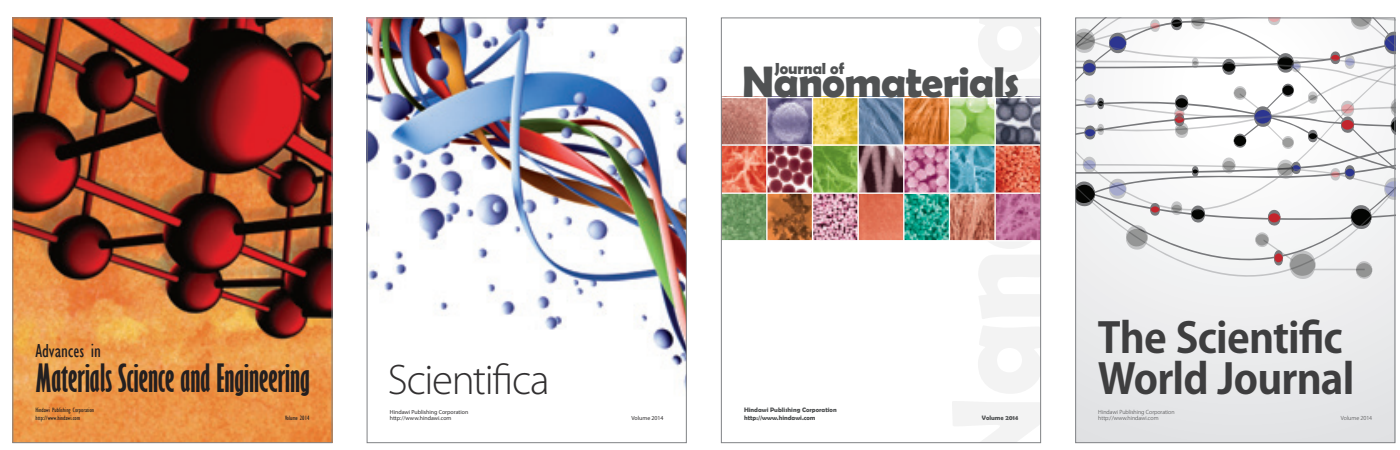

\section{The Scientific World Journal}
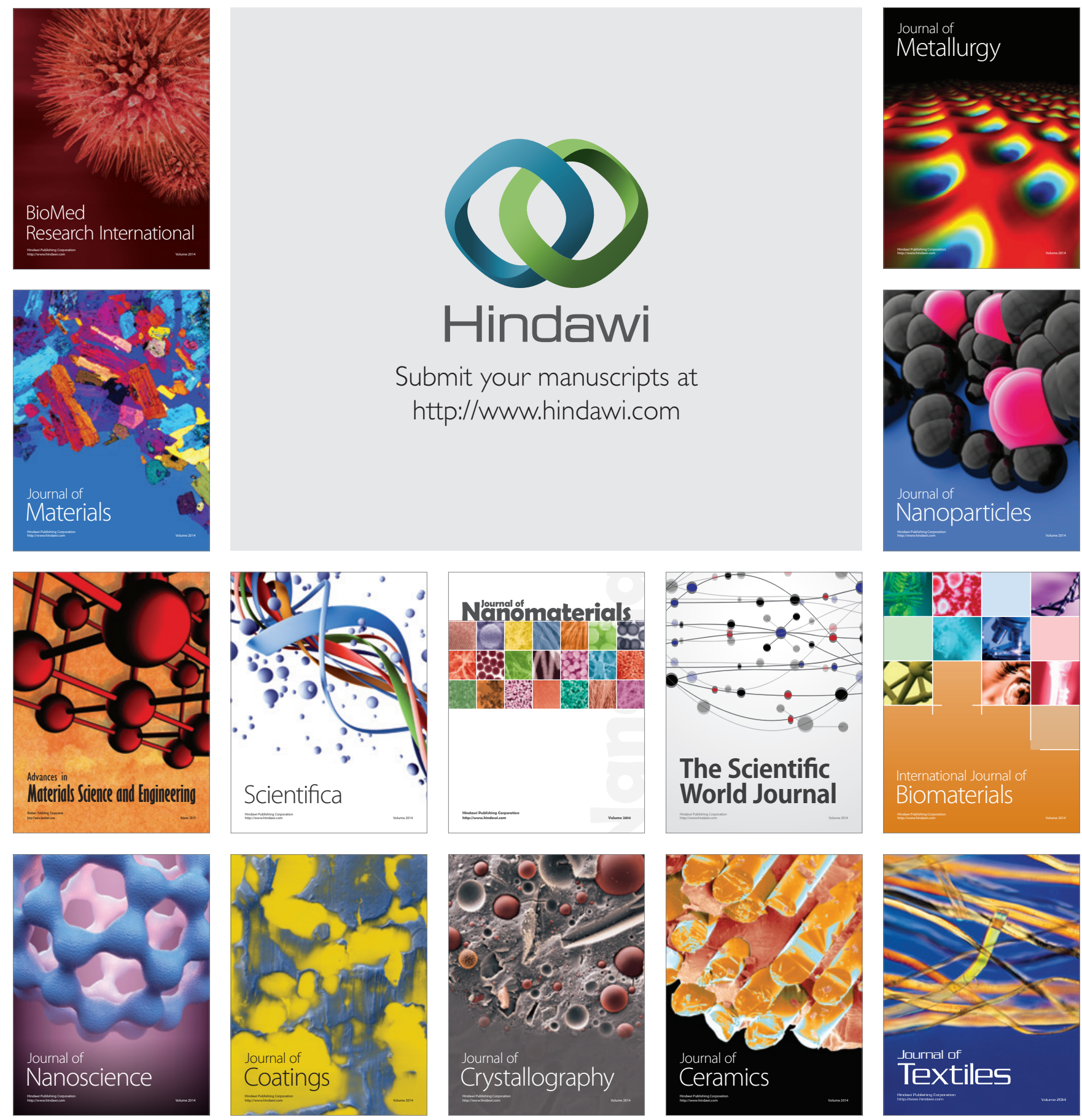